\title{
THE EFFECTIVENESS OF MOTOR CARRIER SAFETY AUDITS
}

\author{
LeON N. Moses and IAN SAVAGE \\ Department of Economics and the Transportation Center, Northwestern University, \\ Evanston, IL 60208-2400, U.S.A.
}

(Received 12 February 1991; in revised form 15 June 1991)

\begin{abstract}
In 1986 the federal government expanded its program of company inspections for enforcement of motor carrier safety regulations. We find that many parts of these inspections are unrelated to the safety performance of firms. Never the less, reinspection of firms found to be unsatisfactory in a previous inspection does appear to bring about a substantial improvement in their safety performance. However, such firms represent a small fraction of the industry, and the probability of being inspected is very low. Thus, the program does not appear to have resulted in a detectable improvement in the accident rate of the industry.
\end{abstract}

\section{BACKGROUND}

Deregulation of the United States interstate motor carrier industry in 1980 brought fears of increased accident rates due to competitive pressure on trucking firms and the influx of new carriers. In response the government enacted legislation that raised minimum quality standards and made more resources available to ensure compliance with the law.

The 1984 Motor Carrier Safety Act and the 1986 Commercial Motor Vehicle Safety Act established national standards for driver and vehicle licensing and provided for increased penalties for violations. Two programs that expanded enforcement were also adopted after 1985. The first was the Motor Carrier Safety Assistance Program (MCSAP), authorized under the 1982 Surface Transportation Assistance Act. It provides federal funds to states to cover $80 \%$ of the cost of motor carrier enforcement activities. These funds increased the number of roadside vehicle inspections by state officials and police from 200,000 in 1984 to over 1.3 million in 1989.* They also allowed the training of enforcement officers to be improved and provided the officers with additional technical support. The program costs the federal government about $\$ 60$ million a year.

Our paper concerns the second program: the overhauling of the system of audits of the safety practices of firms. Starting October 11986 , federally employed inspectors attempted to identify the estimated 185,000 firms, out of a heavy truck industry of more than 200,000 firms, that had not been audited under the previous system, and to conduct audits of their compliance with federal safety laws. $t$ Many of these firms were small operators that had entered interstate commerce after deregulation. In 1987, 24,000 firms were audited, compared with approximately 10,000 per year under the old regime, and by May 1990 just over 60,000 firms had been rated.

Transportation engineers and economists have been engaged in a debate as to whether increased inspections lead to reduced accident rates. Patten, Carroll, and Thomchick (1989) investigated the effectiveness of roadside inspections. Corsi, Fanara, and Roberts (1984) and Corsi and Fanara $(1988,1989)$ have analyzed the safety audit procedure using data from the early 1980s. In this paper we also investigate whether the enhanced program of safety audits has measurable effects on safety. Compared with the studies of Corsi et al. $(1984,1988,1989)$, our study involves a larger sample, takes a more detailed look at the content of the audits, and covers the postexpansion period of the program. In addition, the study employs Poisson rather than ordinary regression

*Summary data presented in this section were obtained from Office of Technology Assessment (1988).

tState employed inspectors in Washington, Oregon, Idaho, and Alaska also conduct safety audits, in a scheme funded by MCSAP. 
techniques. The former are viewed as being more appropriate for the investigation of accidents by most analysts.

The paper has the following structure; section 2 describes the audit process; section 3 describes our data and the analytical techniques used; sections 4 and 5 the relationship between the audit process and the risk that individual carriers pose to society. In section 6 the extent to which the audits result in improved highway safety is examined. We draw our conclusions in section 7 .

\section{THE SAFETY AUDIT PROCESS}

For many years field staff of the Federal Highway Administration (FHWA) had undertaken safety audits. Approximately 10,000 audits a year were undertaken prior to 1984. The audit program was increaed by the 1984 Motor Carrier Safety Act, which placed a requirement on the federal government to inspect all interstate carriers. The expanded program began functioning on October 1, 1986. Authorization was given to double the inspector workforce by hiring 150 extra staff. The transfer of responsibility for roadside inspections to the states under the MCSAP program also released some federal inspectors to conduct audits. ${ }^{*}$ As described in the introductory section, the number of annual audits increased substantially starting in 1987.

The inspectors visit the operating bases of firms and question managers about safety related procedures and policies, such as those governing maintenance, and driver hiring and training. The inspectors do not actually inspect any equipment or test drivers. The FHWA views the initial visit to a carrier as mainly educational and has a policy of not initiating citations for violations found.

The inspectors have a standard list of 75 questions, grouped under nine headings. The inspector marks a "yes" or "no" answer to each question, but can append comments and supporting documentation. The inspectors ask 13 general questions. A sample question in this category is, "Does the individual in charge of safety have authority to terminate drivers?" There is also 1 question on whether the firm has been certified by the government as having a minimum level of financial responsibility; 5 on reporting of accidents ("Can the carrier explain the definition of a reportable accident?"); 13 on driver qualifications ("Can the carrier list the documents required to be in a driver qualification file?"); 5 on driving ("Does the carrier have a policy for monitoring speed?"); 8 on maintenance ("Can the carrier produce the prior three months inspection reports on a vehicle selected at random?"); and 12 on hours of service ("Can the carrier produce the prior 6 months records of duty status for a driver selected at random?"). If the carrier hauls hazardous materials it can also be asked 7 questions on driving and parking rules ("Is the carrier aware of the marking of vehicles requirement?"); and 11 more general questions ("Can the carrier explain the accessibility requirements for shipping papers?").

The carrier is then rated as satisfactory, conditional, or unsatisfactory in each of the nine areas, and finally an overall rating is given to the firm. The FHWA has indicated that the rating is determined by violations found as part of the above audit, roadside inspection records in the past 5 years, infringements of the law, accident rates, and evidence of improvements made by the carrier (Office of Technology Assessment 1988). However, the FHWA has consistently refused to reveal the weights that it applies to the various elements in arriving at the overall rating. Firms that satisfy the inspector but have only recently come to the attention of the FHWA are typically rated conditional pending the establishment of a track record with the Administration. If a firm is found to be unacceptable in any way, a return visit is made to the carrier. These visits are much more detailed, involving 28 staff hours against the 2 to 3 hours for the initial audit. In addition to reexamining the firm on the above questions, the inspectors also determine whether legal enforcement action is necessary and can collect evidence to support any citations. 
There are penalties for failure to comply with federal regulations. Firms can be fined and, in the extreme, banned from offering service. There are also some economic penalties. Some large shippers, such as Chrysler Corporation and the Department of Defense, have policies of contracting only with motor carriers who have been rated "satisfactory" in the federal safety audit. In addition, the Hazardous Materials Transportation Uniform Safety Act of 1990 proposes that shippers of hazardous materials could be made liable for $50 \%$ of the cost of any accident if they use a carrier that has been rated less than satisfactory in a federal audit. If a "satisfactory" firm is used, then only the trucking firm is liable for any accident costs. The same act bars "unsatisfactory" firms from hauling hazardous materials.

\section{DATA SOURCES, FUNCTIONAL FORM, AND VARIABLES USED}

\section{Data sources}

The FHWA maintains a computer database on all the motor carriers that are known to them. The database is known as the Motor Carrier Management Information System (MCMIS). The data include: physical characteristics, goods carried, accident record, and the results of the most recent safety audit. The data for our analysis were supplied by the FHWA and are derived from their MCMIS database. We obtained data on 13,053 firms who were audited between October 1986 and July 1989. Our data represent about a third of the firms who were audited during this period. Our sample size is a considerable improvement on previous work, which typically had sample sizes under 1,000 (Corsi et al. $1984,1988,1989)$.

\section{Functional form}

Previous academic study used ordinary least squares (OLS) regression techniques on accident rates. However, goodness-of-fit was very poor, with adjusted $R^{2} s$ being in the vicinity of 0.15 . Our estimation technique was designed to overcome some of the shortcomings of the earlier work. It is commonly accepted that accident occurrence conforms to a Poisson distribution, and therefore we adopted a Poisson regression in preference to OLS.* In the Poisson formulation the number of accidents is the dependent variable, the explanatory variables are multiplicative, and one takes the exponent of a coefficient in order to interpret it.

\section{Variables employed in the analysis}

The accident experience of the firm in the previous 365 days. Accident data are notoriously unreliable in the trucking industry. The national truck accident database of the FHWA's Office of Motor Carriers is widely believed to have serious inconsistencies and underreporting of damage-only accidents. $\dagger$ Yet these data have been used by many authors. Our data come from questions asked directly of managers by the inspector, and therefore should be more reliable. In addition to analyzing the total accident experience of firms, we carry out a separate investigation of fatalities and injuries. However, here the dependent variable has to be the number of fatalities and injuries that resulted from accidents the firm had in the previous years, because the number of accidents in which a fatality or injury occurs is not reported.

The log of total fleet miles of the firm in the past year. We use these data to capture both the amount of exposure to accidents and any firm size effects on accident rates. Testing of the coefficient against 1 determines whether accidents increase more or less than proportionately with miles. Inclusion of this variable allows us to colloquially refer to "accident rates" when interpreting the coefficients on other explanatory variables.

*Variables of this type cause heteroscedasticity in any OLS regression. A common method of controlling this problem in OLS is to transform the dependent variable by taking its natural logarithm. Since many firms report zero accidents in a given year, a significant problem arises. Corsi et al. add a constant to the accident rate of each firm to avoid this problem.

tAll interstate trucking firms are required to report accidents involving a fatality, an injury, or over $\$ 4,400$ of property damage to the FHWA. 
We did try including a squared term in this variable, but found it to be statistically insignificant.

The percentage of drivers employed on trips over 100 miles. We hypothesized that firms whose primary work involves short distances, typically in urban areas, would have a different accident experience from firms whose operations primarily involve long distance service on the Interstate Highway System. This variable cannot be expressed in logarithms because several firms report zero long distance drivers.

The type of goods hauled. In the audits, firms can mark the type of goods carried, choosing from 25 categories of nonhazardous goods and 21 categories of hazardous goods. They can classify themselves in as many categories as they wish. However, we use only two dummy variables, one for general freight and one for agricultural goods." We consider in a separate paper (Moses and Savage 1991) the accident experience of the $15 \%$ of firms who indicated that they carried hazardous materials.

The log of the years of experience of the firm. A difficulty in this investigation was that the data available to us are dates of incorporation rather than initial year of operation. This restricted analysis of this variable to the two-thirds of firms who are incorporated. It is, of course, true that many firms operated as a sole proprietorship or partnership for many years prior to incorporation. Other authors have tried to base age on the date that carriers were issued their operating rights by the Interstate Commerce Commission (ICC). However, this procedure also has a weakness. Our data reveal that there are corporate firms that operated for years prior to ICC certification.

One might imagine that this variable would be highly collinear with the size of the firm. However, this is not the case. A regression between the logs of the size and experience variable produces an $R^{2}$ of just 0.7 of one percent; and an elasticity, albeit significant, of only 0.15 .

Performance in the Federal Safety Audit. Previous academic studies used variables reflecting the rating of the carriers in each section of the audits (maintenance, hours of service, etc.). Corsi et al. $(1984,1988,1989)$ found that compliance with accident reporting requirements and hours of service regulations were significantly related to accident performance. However, compliance with other areas of the regulations had counter-intuitive signs: the better the compliance rating of firms, the worse their accident rates. Replication of such an analysis using our data gave similar results.

In an effort to understand why such counter-intuitive results were obtained, we decided to introduce directly the answers to the 57 questions asked of all carriers. $\dagger \mathrm{A}$ priori, one would expect that there would be considerable collinearity between the answers to the questions and that techniques such as factor analysis would have to be deployed. In fact, much to our surprise, of the 3,192 possible correlation coefficients only $19(.6 \%)$ are over 0.5 . Only 3 are in excess of 0.7 . All of the correlations over 0.5 occur between questions on the same section of the audit.

We therefore decided that, subject to correcting for the few cases of high collinearity. the audit variables could be entered directly into a regression. The following amalgamations were made to avoid collinearity. The format we follow is one in which the subject matter of the questions is followed in parentheses by a précis of the individual questions. The first listed of the questions is the one that is used to provide the data in the regressions.

"In initial work, dummy variables were used to represent each of the 46 categories. Our findings mirror those of earlier work by Corsi and Fanara (1988) that general freight (including less-than-truckload) operations have significantly higher than average accident rates, and agricultural operations (forest products; livestock: fresh produce: and grain, feed, and hay) have significantly lower than average accident rates. Other cargo categories have marginally significant or insignificant coefficients. An effort was made to explain these differences by looking at the characteristics of the various cargoes. One variable we tried was the value per truckload of the various commodities. The intuition was that shippers of high-valuc goods would be more sensitive to safety. The results failed to support this hypothesis, but the only value data available to us were ten years old.

tA further 18 questions are asked only of hazardous materials carriers and are therefore excluded from the analysis. All questions are worded so that a "no" implies negative safety behavior. Our data are coded such that a no equals 1 and a yes equals 0 . 
Table 1. Characteristics of different ratings

\begin{tabular}{lccc}
\hline & Satisfactory & Conditional & Unsatisfactory \\
\hline Number of firms (\% of total) & $5674(43 \%)$ & $6683(51 \%)$ & $696(5 \%)$ \\
$\%$ of total mileage & $71 \%$ & $23 \%$ & $6 \%$ \\
Average annual miles & $1,409,500$ & 392,990 & 891,810 \\
$\%$ of firms incorporated & $72 \%$ & $54 \%$ & $67 \%$ \\
Ave. years since incorporation & 14.8 years & 13.1 years & 12.2 years \\
Accidents per million miles & 5.284 & 3.128 & 5.632 \\
Fatalities and injuries per & & & \\
$\quad$ million miles & 0.319 & 0.294 & 0.422 \\
\hline
\end{tabular}

(a) Safety director hires/fires drivers? (Does safety director have sole authority to hire drivers? Does the safety director have a right to terminate drivers?)

(b) Medical regulations followed? (Does carrier have a system to kecp medical certificates current? Does the carrier ensure examining physicians know motor carrier requirements? Does carrier review medical histories?)

(c) Hiring documentation in order? (Can carrier list documents to be in driver file? Does carrier ensures driver annual reviews are current? Can carrier explain written test rules? Does carrier comply with road tests? Can carrier produce a driver's file selected at random?)

(d) Knowledge of accident definition? (Can carrier explain definition of reportable accident? Can carrier explain fatal accident reporting requirements?)

(e) Records kept of duty status? (Do drivers hand in duty status records on returning to home base? Does carrier record duty status? Can carrier produce previous 6 months' duty status on driver chosen at random?)

(f) Maintenance records kept? (Can carrier produce maintenance file on a vehicle chosen at random? Does carrier have written maintenance policies? Can carrier list maintenance records required?)

Consequently, performance on audits is represented by 45 dummy variables in our regression.

\section{THE RELATIONSHIP BETWEEN COMPLIANCE AND ACCIDENTS- OVERALL MEANS}

The FHWA has stated that accident rates are considered when assigning a rating to a carrier. It would, therefore, not be surprising to find that firms rated unsatisfactory have the poorest accident record. Comparison of mean accident rates, shown in Table 1 , confirms that unsatisfactory firms do appear to be the ones that pose the greatest threat to society. They have an average accident rate that is $18.6 \%$ above that for the combined conditional and satisfactory firms. In terms of fatalities and injuries per million miles they are $35 \%$ worse. These differences are statistically significant.

Our data also provide insight into the type of firm that is rated conditional.The average conditional firm has annual fleet mileage that is $30 \%$ of that for firms rated satisfactory or unsatisfactory. $54 \%$ of conditional firms are incorporated against $72 \%$ in the other categories. These data are consistent with the audit program's objective of extending the federal database and going beyond the large firms that were licensed by the ICC years ago. Despite the fact that firms rated conditional have only recently come to the attention of the FHWA, it is notable that as a group they have the lowest average accident rate.

\section{THE RELATIONSHIP BETWEEN COMPLIANCE AND ACCIDENTS- MULTIPLE REGRESSION}

The results of the regressions for total accidents and total fatalities and injuries are shown in Table 2 . The percentages of variation in the dependent variable explained by 
Table 2. Regression of firm characteristics and compliance with safety regulations on accident and fatality and injury rates

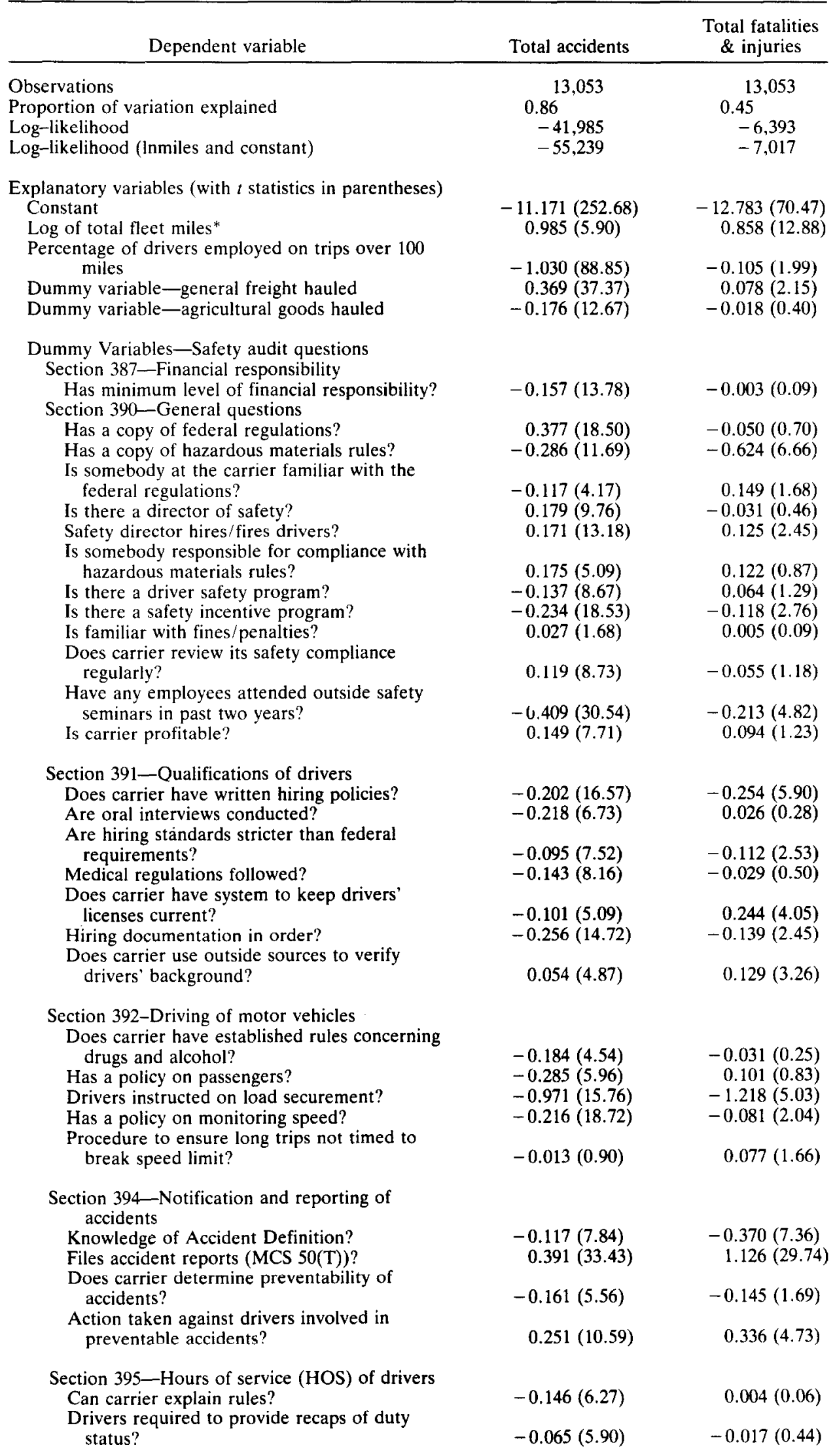


Table 2. (Continued)

\begin{tabular}{lcc}
\hline \multicolumn{1}{c}{ Dependent variable } & Total accidents & $\begin{array}{c}\text { Total fatalities } \\
\text { \& injuries }\end{array}$ \\
\hline Monitors HOS of trip lease drivers? & $0.131(0.42)$ & $0.055(0.54)$ \\
Dispatchers aware of HOS? & $-0.181(11.13)$ & $0.164(3.13)$ \\
Drivers required to 'phone in daily? & $0.485(27.83)$ & $0.099(1.42)$ \\
Are drivers' records of duty status & $0.060(4.83)$ & $-0.087(1.97)$ \\
$\quad$ independently checked? & $0.183(10.18)$ & $0.011(0.18)$ \\
Records kept of duty status? & $-0.012(0.60)$ & $0.109(1.44)$ \\
Monitors HOS of local trip drivers? & $0.071(5.03)$ & $0.106(2.21)$ \\
Has system to monitors drivers' HOS? & $0.098(6.86)$ & $-0.181(3.59)$ \\
Disciplinary action taken against drivers who & & \\
$\quad$ violate HOS rules? & & \\
& & \\
Section 396-Inspection, repair and maintenance & & $0.013(0.23)$ \\
Reviews maintenance records of leased & & $0.089(1.61)$ \\
$\quad$ equipment? & $-0.422(2.43)$ & $0.118(1.05)$ \\
Complies with inspection rules? & $0.270(17.12)$ & $-0.153(2.83)$ \\
Drivers perform pre-trip inspection? & $-0.209(0.57)$ & $-0.072(0.88)$ \\
Can produce prior 3 months inspection records & & \\
$\quad$ on randomly chosen vehicle? & $-0.619(3.99)$ & $0.125(2.70)$ \\
Are all vehicles inspected at home base on a & & \\
$\quad$ periodic basis? & $-0.160(5.79)$ & $-0.246(16.79)$ \\
Maintenance records kept?
\end{tabular}
dent rate.

*The coefficient on miles is compared against 1 so as to determine the effect of fleet miles on acci-

the regression* and the log-likelihood statistic are presented. The latter statistic is usually compared to the log-likelihood of a regression with only a constant. However, because total accidents are heavily related to exposure we felt that the most enlightening comparison would be a regression with a constant and the log of fleet miles.

Both the accident and the fatalities and injuries equations show impressive loglikelihood tests. However, the latter equation has poorer predictive powers. This is not surprising, since two levels of randomness are introduced in determining fatalities and injuries. The first is whether any particular accident results in fatalities or injuries. For example, whether a brake failure on a hill results in injuries or fatalities may depend very much on whether there is a sharp bend at the bottom. A second level of randomness is the number of fatalities or injuries that occur. To extend our example, it depends on whether there is a field or a school on that sharp bend. $\dagger$

\section{Interpretation of inspection variables' coefficients}

Coefficients in the accident equations. With regard to compliance with regulations, one would expect positive coefficients. The implication is that the worse the performance on a question, the higher the accident rate. There are a number of issues strongly related to accident occurrence. These include: the appointment of a safety director with control over hiring and firing drivers; obtaining independent verification of the background of new hires; the filing of accident reports with the government and disciplining drivers involved in "preventable" accidents; monitoring drivers' hours-of-service and having the information available to dispatchers; and having regular inspection of vehicles and keeping good maintenance records.

However, the overall conclusion is that the worse a firm does on a large part of the audit, the better its accident record! In particular, all of the questions dealing with financial responsibility and driving practices, and a large proportion of the questions dealing with the qualifications of drivers and maintenance are counter-intuitively related

*This is sometimes referred to as a "pseudo $\mathbf{R}^{2}$."

tThe implication is that the number of fatal or injury accidents rather than the total number of fatalities and injuries is a better measure for cross-firm comparisons. Surprisingly, the inspectors do not ask for this piece of information. 
Table 3. Predictive power of variables in equations

\begin{tabular}{lcccccc}
\hline & \multicolumn{2}{c}{ Accidents } & & \multicolumn{2}{c}{ Fatalities and injuries } \\
\cline { 2 - 3 } & \% Variation & Log-likelihood & & \% Variation & Log-likelihood \\
\hline $\begin{array}{l}\text { Exposure + characteristics } \\
\begin{array}{l}\text { Exposure + characteristics } \\
+ \text { inspection }\end{array}\end{array}$ & 0.82 & $-47,269$ & & 0.24 & $-6,997$ \\
\hline
\end{tabular}

to accident performance. Many of these counter-intuitive coefficients are also statistically significant.

Some explanation for this latter conclusion comes from informal conversations with the inspectors. They have told the authors that many small firms are unaware of the federal regulations, and hence do not maintain the necessary paperwork to pass the audit, yet have good and safe business practices. Information about regulations is usually communicated through the trade association, the American Trucking Associations, which many small firms do not join. In contrast, there are larger firms that are familiar with the audit process and hence can arrange to have the documents to support a "yes" answer to the questions on the audit, even if the relevant safety practices are not in place.*

Proportion of variation explained. One method of evaluating the effectiveness of safety audits is to determine how much of the variation in the accident variables is explained by the inspection as opposed to other factors. Therefore, the decision was made to run two regressions for both the overall accidents and for the fatalities and injuries variable. The first contains only the exposure variable (log of fleet miles) and the firm characteristic variables; the second adds the inspection variables. Table 3 shows the percentage of variation explained and the log-likelihood for each. In log-likelihood terms, the addition of the inspection variables is statistically highly significant. In the accident equation, exposure and the characteristics of the firm explain the vast majority of the variation. The inspections then account for a quarter of the remaining unexplained variation, or $4 \%$ of the total variation.

The conclusion appears to be quite the opposite in the fatalities and injuries equation. The random effects that we have referred to before are so large in this equation that exposure and firm characteristics explain only $24 \%$ of the variation. The addition of the inspection variable almost doubles the explanatory power. Compliance with regulations regarding accident reporting, recording of drivers' hours-of-service, keeping vehicle maintenance records, and making background checks on new hire drivers appear to be particularly effective indicators of a firm's potential to kill or maim people.

Comparison with the issues that the inspectors consider important. A second method of evaluation is a comparison of those sections of the audit that our analysis indicates are significantly related to accidents with the sections that the inspectors consider important in assigning an overall rating to the carrier. As we indicated above, the FHWA has consistently refused to reveal the "formula" that it uses to rate a carrier. As part of our study we decided to apply statistical techniques in an effort to gain some insight into the rating scheme.

We have data only on some of the relevant variables used in making the determination of a rating: the accident rate and the answers to the 45 questions. Since the inspectors can give only three grades we adopt a sequential logit approach. $\dagger$ A firm is first judged to have either passed (received a conditional or satisfactory rating) or to have failed (rated unsatisfactory). The logit technique is then used a second time to separate the satisfactory from the conditional firms. $91 \%$ of firms are correctly classified in the first step and $73 \%$ in the second. The reader is cautioned that, because we are

*We have been informed that there are consulting companies who will advise trucking firms in how to pass the audit. choice.

tA nested logit procedure would be equally suitable, however computer space restrictions dictated our 
missing several important variables, it is possible that econometric problems may be present in this procedure.

The results are shown in Table 4. One would expect the coefficients to be negative, in that having a higher accident rate or being judged a "no" on a given question should result in being given a poorer rating by the inspector. That is not entirely the case. The accident rate is not related to the rating issued to a carrier. Although we expected some insignificant variables, since the FHWA may not attach any weight to some questions, the number of counter-intuitive and significant coefficients in our logit regressions is surprising. We attempted to replicate the decision process of the FHWA in deciding a rating, and hence did not include a constant term in our regressions. Thus the $\rho^{2}$ and log-likelihood measures of fit should be interpreted cautiously.

The results of Tables 2 and 4 are combined in Table 5. This shows all the questions that have statistically significant, intuitively correct coefficients. We indicate the calculated percentage effect on accident rates of being assessed a "no," whether the question is regarded as important by the inspectors, and also the percentage of firms that are given a "no" answer.

It is pleasing to note that in a large number of cases the inspectors appear to weight heavily those questions that are significantly related to accident occurrence, particularly those dealing with accident reporting, hours of service, and maintenance. It is also reassuring to know that the inspectors place no weight on financial responsibility and driving rules that are unrelated to accidents.

However, the federal inspectors appear to have mistakenly ignored the effect of the appointment of a safety director and, instead, incorrectly concentrated on the existence of driver safety training. On the issue of hiring, the inspectors appear to have mistakenly placed emphasis on paperwork violations in the hiring process and ignored the effectiveness of background checks in preventing accidents. It is also curious that, while compliance with accident reporting is rightly considered important in the identification of unsatisfactory firms, this is not so in the differentiation between conditional and satisfactory ones. This is especially surprising given the strong relationship between accident and fatality-and-injury rates and noncompliance with these regulations.

In support of our conclusions, inspectors have told the authors that the hours-ofservice regulations appear to be the most important factor both in determining the rating and as an indicator of the safety practices of firms. ${ }^{*}$ Also, the inspectors were not surprised by the poor performance of some of the questions on maintenance. Federal regulations specify "regular maintenance" but are very vague on what this actually means, thereby allowing variation due to differing state and local legislation.

\section{Interpretation of firm characteristic coefficients}

Firm size. The results reported in Table 2 reveal that accidents rates decline with firm size, as measured by total fleet miles. The coefficient has a value significantly less than unity, meaning that accidents rise less than proportionately with miles. The size effect is also found in the fatalities and injuries regression. The greater safety of larger firms is even more pronounced here. The results that we report for accidents, and fatalities and injuries are in accord with generally held folklore on large firms; namely, that they are safer than small and medium-sized firms, presumably because there are economies of scale in the production of quality service, including safety. We will shortly question the folklore and suggest an important amendment to it.

Long distance and agricultural operations. Long distance and rural operations, as evidence by the agricultural goods dummy variable, have lower accident rates than other firms by $64 \%$ and $16 \%$, respectively. $\dagger$ However, there is no evidence of reduced fatality

\footnotetext{
*The formula for weighting the various questions to obtain a rating is such a closely guarded secret that even the inspectors do not know it.

tThe lower accident rates of agricultural carriers may be due to the fact that they do not have to keep records on accidents occurring in farm-to-market trips.
} 
Table 4. Sequential logit model of compliance with safety regulations on overall rating ( $\mathrm{S}=$ Satisfactory, $\mathrm{C}=$ Conditional, $\mathrm{U}=$ Unsatisfactory)

Dependent variable
Sample size
$\rho^{2}$
Likelihood Ratio Test: $\mathrm{X}^{2}=$
Proportion of observations correctly predicted
Explanatory variables (with $t$ statistics in parentheses)

Accident rate

\begin{tabular}{cc} 
Level 1 & Level 2 \\
\hline $\mathrm{C} / \mathrm{S}=1$ & $\mathrm{~S}=1$ \\
$\mathrm{U}=0$ & $\mathrm{C}=1$ \\
\hline 13,053 & 12,357 \\
-0.315 & 0.319 \\
-1712 & 5455 \\
0.91 & 0.78
\end{tabular}

Dummy variables-Safety audit questions

Section 387-financial responsibility

Has minimum level of financial responsibility?

Section 390-General questions

Has a copy of federal regulations?

Has a copy of hazardous materials rules?

Is somebody at the carrier familiar with the federal regulations?

Is there a director of safety?

Safety director hires/fires drivers?

Is somebody responsible for compliance with hazardous materials rules?

Is there a driver safety program?

Is there a safety incentive program?

Is familiar with fines/penalties?

Does carrier review its safety compliance regularly?

Have any employees attended outside safety seminars in past two years?

Is carrier profitable?

$$
-0.003(1.77)
$$

$0.040(12.19)$

$0.976(14.15)$

$0.531(11.06)$

$0.108(1.21)$

$0.445(2.90)$

$-0.048(0.76)$

$0.403(3.90)$

$-0.283(2.53)$

$0.137(0.98)$

$1.107(6.58)$

$-0.502(5.12)$

$-0.120(1.14)$

$0.515(5.27)$

$-0.169(0.65)$

$0.251(1.32)$

$-0.287(3.44)$

$0.923(13.12)$

$0.355(4.05)$

$-0.145(2.51)$

$0.597(11.70)$

$0.126(2.05)$

$0.004(0.05)$

$-0.207(3.75)$

$0.955(13.51)$

$0.423(8.45)$

$0.556(3.82)$

$0.445(4.82)$

Section 391-Qualifications of drivers

Does carrier have written hiring policies?

Are oral interviews conducted?

Are hiring standards stricter than federal requirements?

Medical regulations followed?

Does carrier have system to keep drivers licenses current?

Hiring documentation in order?

Does carrier use outside sources to verify drivers' background?

$0.523(6.92)$
$-0.441(4.11)$

$0.232(3.03)$

$-0.302(3.42)$

$-0.610(6.44)$

$0.058(0.69)$

$0.884(12.21)$

$0.026(0.14)$

$-0.216(1.35)$

$0.226(0.64)$

$0.528(7.30)$

$0.663(6.30)$

$0.321(4.13)$

$-1.074(13.34)$

$-0.089(0.67)$

$-1.143(9.86)$

$-0.686(6.58)$

$1.152(16.29)$

$0.002(0.01)$

$-0.769(8.06)$

$0.387(3.35)$
$0.288(5.48)$

$-0.482(5.24)$

$0.049(0.93)$

$-0.362(5.55)$

$-0.347(4.72)$

$-1.026(18.12)$

$0.521(10.07)$

$-0.173(1.14)$

$-0.037(0.28)$

$0.313(1.22)$

$0.271(5.34)$

$0.336(4.94)$

$-1.250(23.34)$

$0.034(0.48)$

$0.124(1.15)$

$0.298(2.92)$

$-0.314(3.23)$

$0.503(10.37)$

$0.268(1.79)$

$-0.316(4.03)$

$0.015(0.18)$

Dispatchers aware of HOS?

Drivers required to 'phone in daily? 
Table 4. (Continued)

\begin{tabular}{|c|c|c|}
\hline & Level 1 & Level 2 \\
\hline \multicolumn{3}{|l|}{ Are drivers' records of duty status } \\
\hline $\begin{array}{l}\text { Independently checked? } \\
\text { Records kept of duty status? }\end{array}$ & $\begin{array}{r}0.051(0.64) \\
-0.520(5.52)\end{array}$ & $\begin{array}{l}-0.254(4.08) \\
-0.644(8.44)\end{array}$ \\
\hline Monitors HOS of local trip drivers? & $-0.019(0.19)$ & $-0.428(4.89)$ \\
\hline Has system to monitors drivers' HOS? & $-0.021(0.24)$ & $-0.454(7.40)$ \\
\hline $\begin{array}{l}\text { Disciplinary action taken against drivers who } \\
\text { violate HOS rules? }\end{array}$ & $-0.098(1.13)$ & $-0.342(5.83)$ \\
\hline \multicolumn{3}{|l|}{$\begin{array}{l}\text { Section } 396 \text {-Inspection, repair, and } \\
\text { maintenance }\end{array}$} \\
\hline \multicolumn{3}{|l|}{ Reviews maintenance records of leased } \\
\hline Complies with inspection rules? & $-0.335(3.60)$ & $-0.145(2.04)$ \\
\hline $\begin{array}{l}\text { Drivers perform pre-trip inspection? } \\
\text { Can produce prior } 3 \text { months inspection records }\end{array}$ & $-0.210(1.34)$ & $-0.278(1.85)$ \\
\hline on randomly chosen vehicle? & $-0.027(0.31)$ & $-0.271(4.28)$ \\
\hline $\begin{array}{l}\text { periodic basis? } \\
\text { perise all a }\end{array}$ & $-0.223(1.81)$ & $-0.107(1.02)$ \\
\hline Maintenance records kept? & $0.165(2.13)$ & $-0.766(14.27)$ \\
\hline
\end{tabular}

and injury rates for agricultural operations, and an estimated $10 \%$ reduction for long distance operations is just marginally significant at the $5 \%$ level. This result is not surprising. Short-distance, congested urban traffic engenders many accidents, but the relatively low speeds mean that serious injuries and fatalities are relatively rare. Agricultural goods move on rural undivided highways, which have relatively few accidents, but those that do occur are often very serious, involving head-on collisions at speed (UMTRI 1987).

General freight operations. General freight carriers, those firms who hold themselves open to carry many different commodities, constitute a large part of the trucking industry. They account for $43.5 \%$ of the total miles recorded in our sample. Table 2 reveals that these carriers have a total accident rate that is $45 \%$ higher and a fatality injury rate that is $8 \%$ higher than the rates of specialized carriers. There are intuitive reasons for believing that general freight carriers are more accident-prone than firms that specialize in a narrow class of commodities. It seems likely that the latter firms develop considerable skill in the carriage of those commodities and acquire a reputation for providing reliable, safe service to their customers. This suggests there are diseconomies of scope in safety.

In explaining this result we were mindful that the term "general freight" covers a variety of operations. One of these is less-than-truckload (LTL) service. ${ }^{*}$ It tends to be associated with regularly scheduled terminal-to-terminal operations, which one would imagine are relatively safe. The capital intensity and economies of size inherent in LTL service mean that it is dominated by large firms. Smaller general freight firms tend to concentrate on truckload operations. Here, a shipper usually has exclusive use of the vehicle on any trip, but the carrier may seek many different types of traffic for different trips.

To incorporate our belief that the general freight category contains several distinct segments, we replace the single, general freight dummy of Table 2 with a series of ten dummies. Each represents an interaction between firm size, measured in deciles, with the general freight dummy. + For the sake of brevity, the full regression results are not reported. The dummy variables indicate increased accident rates for all but the eighth decile. In ascending order of firm size, the percentage changes are: $121 \%, 87 \%, 18 \%$, $39 \%, 29 \%, 38 \%, 8 \%,-22 \%, 48 \%$, and $55 \%$. These changes are based on statistically significant coefficients. The results confirm the belief that small general freight firms

* Where small loads are consolidated in a hub-and-spoke system for long hauls.

†A measure of the well-known skewed nature of firm sizes in this industry is indicated by the fact that the mean firm size lies in the ninth decile. 
Table 5. Summary of significant, intuitively signed inspection variablest

\begin{tabular}{|c|c|c|c|c|c|}
\hline & (1) & (2) & (3) & (4) & (5) \\
\hline \multicolumn{6}{|l|}{ Section $390-$ General questions } \\
\hline Has a copy of federal regulations? & 33 & 46 & & & \\
\hline $\begin{array}{l}\text { Is somebody at the carrier familiar with the } \\
\text { federal regulations? }\end{array}$ & 17 & & & * & * \\
\hline Is there a director of safety? & 8 & 20 & & & \\
\hline Safety director hires/fires drivers? & 7 & 19 & 13 & & \\
\hline Is somebody responsible for compliance with & & & & & \\
\hline hazardous materials rules? & 2 & 19 & & & \\
\hline Is there a driver safety program? & 34 & & & * & * \\
\hline Is familiar with fines/penalties? & 29 & 3 & & & \\
\hline Does carrier review its safety compliance & & & & & \\
\hline regularly? & 47 & 13 & & & * \\
\hline Is carrier profitable? & 7 & 16 & & & \\
\hline \multicolumn{6}{|l|}{ Section 391-Qualifications of drivers } \\
\hline Does carrier have written hiring policies? & 15 & & & * & \\
\hline Are oral interviews conducted? & 14 & & & & * \\
\hline Medical regulations followed? & 32 & & & * & * \\
\hline \multicolumn{6}{|l|}{ Does carrier have system to keep drivers' } \\
\hline licenses current? & 23 & & 28 & * & * \\
\hline Hiring documentation in order? & 47 & & & & * \\
\hline Does carrier use outside sources to verify & & & & & \\
\hline drivers' background? & 62 & 6 & 14 & & \\
\hline \multicolumn{6}{|l|}{$\begin{array}{l}\text { Section 394-Notification and reporting of } \\
\text { accidents }\end{array}$} \\
\hline Knowledge of accident definition? & 52 & & & & $*$ \\
\hline Files accident reports (MCS 50(T))? & 14 & 48 & 207 & * & \\
\hline $\begin{array}{l}\text { Action taken against drivers involved in } \\
\text { preventable accidents? }\end{array}$ & 8 & 28 & 40 & * & \\
\hline \multicolumn{6}{|l|}{ Section 395-Hours of service (HOS) of drivers } \\
\hline Can carrier explain rules? & 15 & & & * & * \\
\hline Dispatchers aware of HOS? & 19 & & 18 & * & * \\
\hline Drivers required to 'phone in daily? & 13 & 62 & & & \\
\hline Are drivers' records of duty status & & & & & \\
\hline independently checked? & 48 & 6 & & & * \\
\hline Records kept of duty status? & 23 & 20 & & * & * \\
\hline Monitors HOS of local trip drivers? & 14 & & & & * \\
\hline Has system to monitors drivers' HOS? & 39 & 7 & 11 & & * \\
\hline Disciplinary action taken against drivers who & & & & & \\
\hline violate HOS rules? & 48 & 10 & & & $*$ \\
\hline \multicolumn{6}{|l|}{ Section 396-Inspection, repair, and maintenance } \\
\hline Complies with inspection rules? & 28 & 31 & & * & * \\
\hline $\begin{array}{l}\text { Can produce prior } 3 \text { months inspection records } \\
\text { on randomly chosen vehicle }\end{array}$ & 36 & & & & * \\
\hline Maintenance records kept? & 45 & & 13 & & * \\
\hline
\end{tabular}

Column (1): Percent of firms assessed a "No" by inspector.

Column (2): Percent increase in total accident rate of being assessed a "No"

Column (3): Percent increase in fatality and injury rate of being assessed a "No".

Column (4): ${ }^{*}=$ Important variable in deciding whether a firm is rated satisfactory/conditional versus unsatisfactory.

Column (5): ${ }^{*}=$ Important variable in deciding whether a firm is rated satisfactory versus conditional.

have particularly severe safety problems. However, contrary to folklore, the declining accident rate with firm size is reversed in the largest two decile groups.

The apparently U-shaped function is better illustrated in Table 6, which also involves deciles of firm size. For each decile, the data are separated into two parts, those firms that indicated that they are involved in general freight operations and those that did not. Mean accident rates and standard deviations are computed and compared for firms of similar size, using $t$ tests. The size results shown in this table are essentially the same as those that were derived using the ten dummy variables. General freight accident rates decline from the first through the eighth deciles, but they are always above those for 
Table 6. Comparison of general freight and other carriers

\begin{tabular}{rcccccc}
\hline & & & \multicolumn{4}{c}{ Accidents per Million Miles } \\
\cline { 4 - 7 } Decile & $\begin{array}{c}\text { Fleet miles } \\
\text { range (000s) }\end{array}$ & $\begin{array}{c}\text { \% firms } \\
\text { gen. frt. }\end{array}$ & Gen. frt. & Other & Ratio & $t$ Stat \\
\hline 1 & -50 & 12.4 & 11.16 & 3.55 & 3.15 & 4.37 \\
2 & $50-76$ & 13.7 & 8.42 & 3.53 & 2.38 & 3.21 \\
3 & $76-100$ & 17.4 & 4.42 & 3.03 & 1.46 & 2.57 \\
4 & $100-140$ & 20.4 & 5.70 & 3.88 & 1.47 & 1.95 \\
5 & $140-200$ & 22.3 & 5.18 & 2.97 & 1.74 & 3.86 \\
6 & $200-300$ & 25.9 & 5.61 & 3.23 & 1.74 & 5.65 \\
7 & $300-450$ & 26.4 & 4.40 & 3.59 & 1.22 & 0.95 \\
8 & $450-725$ & 29.8 & 4.49 & 3.00 & 1.50 & 3.57 \\
9 & $725-1400$ & 35.4 & 4.48 & 3.87 & 1.16 & 0.34 \\
10 & $1400-$ & 45.4 & 7.12 & 3.38 & 2.10 & 9.57 \\
\hline
\end{tabular}

nongeneral freight firms. Carriers in the ninth decile have essentially the same average accident rates as those in the eighth, a minor difference from the results using dummy variables. The largest general freight firms, those in the final decile, have an average accident rate that is significantly higher than the ninth decile, with a $t$ statistic of 7.8 . It is instructive to note that the high accident rates for the smallest and largest firms are not evident for nongeneral freight firms. *

Interpretation of the general freight result for the smallest carriers is relatively easy. One can imagine that the best of the small firms would trade in specialized markets where they can build a reputation for good service. Poor firms would be attracted to the gencral freight truckload market where there are many transient shippers.

The turn up in accident rates for general freight firms in the two top deciles is not, in our view, the result of a diseconomy of scale. The accident rates of nongeneral freight firms of similar size do not exhibit this pattern. The implication is that the largest general freight firms carry the largest number of different commodities. They are the very large LTL carriers. However, it must be borne in mind that this result is for the total number of accidents and is not repeated for the number of fatalities and injuries associated with those accidents. The turn up in accident rates to which we have referred is solely the result of property-damage accidents. Support for our hypotheses has come from practitioners. They suggest that large LTL firms have to visit premises of many and varied shippers whose freight may require different handling. As a result, they are open to more property-damage accidents. We do have a dummy variable in our regressions that indicates urban operations, but the implication is that the urban effect is far more pronounced for these large LTL carriers. We received some data from two large LTL firms which confirmed that the local "pick up and delivery" part of their operations was far more accident-prone than the "line haul" segment. The magnitude of the difference was large; for one firm, local work had accident rates 5 times higher than those of long distance hauls, and for the other firm, 12 times higher.

Our conclusion for the largest group of general freight firms may help to reconcile our finding of economies of scale in safety in Table 2 with the evidence of the FHWA that, based on audit information, firms with fleets of more than 100 vehicles have twice the accident rate of smaller firms (U.S. Senate 1989a). As has been shown in Table 6, large firms are proportionately more attracted to general freight than smaller firms. General freight firms in the tenth decile account for $39 \%$ of the total fleet miles and are ten times larger than all other firms in our sample.

Firm age. We also decided to investigate the effect of firm age on accident performance, using as our variable the number of years since incorporation. Unfortunately, one-third of the firms in our sample are not incorporated, and hence regressions including

* Results using the dummy variables and the comparison of means analyses for fatality and injury rates yielded less insight and are not reproduced here. With the exception of significantly high rates for the smallest general freight firms, the results are weak because, as we commented earlier, fatality and injury rates exhibit great variability. 
this variable are restricted to corporate firms. The full regressions are not included for the sake of space and because the incorporation of this variable does not have a noticeable effect on other coefficients. In the total accident regression, the coefficient is 0.166 , with a $t$ statistic of 28.91 , and in the fatalities and injuries equation it is 0.053 with a $t$ statistic of 2.36. Our results, for total accidents as well as fatalities and injuries, suggest that older firms have a worse accident rate than new firms.

This result is counter-intuitive and also contrary to the findings of Corsi and Fanara (1989), who found a learning curve effect in firms' accident behavior: the accident rates of newly established firms declined over time, so that by the fifth year they had rates that approximated those of firms that had been in business much longer. One possible insight into the experience result is provided by the economic analysis of reputation. When consumers lack perfect knowledge about quality they base their current demand on either the previous experience they have had in dealing with the carrier, or word-ofmouth recommendations. Large, well established carriers have built a reputation. Newer firms may have to provide very high quality, safe, service in order to acquire a reputation. Hence, it may be optimal for new firms to overinvest in quality so as to effectively compete in the market (Shapiro 1982).

\section{THE SAFETY IMPLICATIONS OF THE AUDIT PROGRAM}

\section{The probability of being inspected}

Since 1984, the annual budget of the operations section of the Office of Motor Carriers has increased from about $\$ 11$ million to $\$ 23$ million in real terms. An additional 150 inspectors were hired with the objective of identifying and assigning safety ratings to the $80 \%$ of the interstate trucking firms that had not previously been audited by the government. The FHWA set a target date of September 30, 1992 to complete initial audits of the estimated 213,000 firms in the interstate trucking industry. The U.S. General Accounting Office (1991) found that by May 1990 only 84,300 firms had been audited, and there was little prospect of the FHWA's meeting its target completion date.

The Congressional Research Service (U.S. Senate Committee on Commerce, Science and Technology 1989) argues that the FHWA has been overloaded with work and that the Agency is top heavy with many "chiefs" and few "indians." They estimate that at least another 10 years will be needed to identify and rate all interstate trucking firms.

\section{Probability and consequences of reinspection}

While the initial compliance review is regarded as mainly educational and friendly in nature, firms that are found to be deficient are faced with the prospect of a return visit. In theory, this visit should occur either 6 months or 1 year later. It is much more detailed, and this time the inspector collects evidence on failure to comply with regulations, which may then be pursued in civil proceedings in the courts.

However, in practice, firms can reasonably expect that the follow-up visit will not occur for several years. The U.S. General Accounting Office (1991) describes followup inspections as "limited and untimely." They found that only $61 \%$ of firms initially assigned an unsatisfactory rating and $10 \%$ of firms rated conditional had received a follow up visit.

In addition to the low probability of detection, the program is perceived to have few teeth. It is the stated objective of the FHWA that the initial audit be mainly educational in nature and that enforcement actions will not be initiated based on violations that are brought to light. These audits have come to be known as the "social hour" by the industry. Enforcement actions result only from follow-up audits. Even then, the enforcement record is poor. About 500 successful convictions occur each year and the average penalty is only $\$ 4,000$. The Congressional Research Service concludes that most firms regard this as a small cost of doing business, given the rarity of a visit by a federal inspector. 
Table 7. Analysis of multiple inspections

\begin{tabular}{lllll}
\hline & & \multicolumn{2}{c}{$\begin{array}{c}\text { Average number } \\
\text { of noes }\end{array}$} & \\
\cline { 3 - 4 } & & First & Second & $t$ Stat \\
\hline Section 390 & General & 2.82 & 1.19 & 8.13 \\
Section 387 & Financial responsibility & $\mathbf{0 . 1 4}$ & 0.07 & 2.39 \\
Section 391 & Qualification of drivers & 5.94 & 3.21 & 9.11 \\
Section 392 & Driving of motor vehicles & 0.66 & 0.28 & 5.35 \\
Section 394 & Reporting of accidents & 1.39 & 0.51 & 7.57 \\
Section 395 & Hours of service & 5.00 & 3.35 & 6.76 \\
Section 396 & Maintenance & 2.02 & 0.79 & 7.45 \\
\hline
\end{tabular}

\section{Safety implications of reinspection}

The inspections dataset employed in the work just reported shows the results of only the most recent inspection for each firm. As firms are reinspected, the new data is written over the old. We were, however, able to obtain a tape of all the inspections carried out for parts of 1988 and 1989; 233 firms are identified as having been inspected more than once. ${ }^{*}$ From the data it is clear that some firms that had been rated satisfactory and conditional were also reinspected. However, the primary focus is firms that were originally rated unsatisfactory. Such firms are 12 times more likely to be reinspected than firms rated in higher categories.

Firms' safety procedures improve significantly by their second inspection. An indication of this is shown in Table 7. The average number of questions that were judged "no" on each part of the first and second inspections are calculated and compared using differences of paired samples techniques. The improvement is not only evident in firms' performance on each part of the inspection and also in their overall rating. Overall, $70 \%$ of the firms that were rated unsatisfactory in the initial visit had an improved rating when they were revisited. The FHWA reports similar figures. In evidence to the U.S. Senate Appropriations Committee (1989) the FHWA reported that of their sample of 975 reinspections, $82 \%$ of firms improved their ratings. Forty percent of the $18 \%$ that did not improve had citations brought against them.

Taking the average proportion of "noes" recorded for each of the individual questions in the first and second inspections and substituting into the estimated equations in Table 2 allow us to calculate the effect on accidents of the threat of a repeat inspection. However, because of the counter-intuitive signs on most of the inspection variables, the equation predicts that accident rates will increase by $40 \%$ and fatality and injury rates by $4.5 \%$ !

We therefore decided to accept the inspection variables whose coefficients were significant and had intuitively correct signs. In addition, we assumed that improvements in other areas of the inspection neither increased or decreased the accident rate. Based on these assumptions, the effect of the second inspection is a decline in accident rates of $30.09 \%$ and in fatality and injury rates of $30.94 \%$.

Support for the latter conclusions comes from results using the overall rating given to the carrier in the two inspections. A pair of regressions on the full 13,053-firm dataset is estimated in a way similar to that reported in Table 2 . However, the inspection variables are replaced by two dummy variables indicating whether the firm was given a conditional or satisfactory overall rating. $\dagger$ In doing so, we recognize the small possibility of simultaneous equation bias, as accidents are part of the inspectors' determination of a rating. Given the relative mileage operated by firms with conditional and satisfactory ratings and that only $70 \%$ of reinspected firms improve, these regressions suggest that the effect of the second inspection is to improve accident rates by $10.4 \%$ and fatality and injury rates by $16.2 \%$.

${ }^{*}$ Firms that were reinspected a few days or weeks later are excluded. We believe that the inspector was probably concluding unfinished business from an initial inspection in these cases.

$\dagger$ The regression results are available from the authors and are not reproduced here for the sake of brevity. 
Table 8. Effect of multiple inspections on accidents

\begin{tabular}{lcc}
\hline & \multicolumn{2}{c}{ Rates per million miles } \\
\cline { 2 - 3 } & Accidents & Fatalities \& injuries \\
\hline Conditional and satisfactory & 4.7506 & 0.3127 \\
Unsatisfactory & 5.6324 & 0.4221 \\
Unsatisfactory with improvement & 3.9376 & 0.2915 \\
\hline
\end{tabular}

Our preference is for the results derived from just looking at those parts of the inspection that are intuitively related to accidence experience. We believe that these results are superior to those reported in the preceding paragraph because we have already demonstrated that the FHWA's formula by which the rating is determined leaves something to be desired. Using the preferred results, the effectiveness of the audit program can be summarized in Table 8 . The table is based on the assumption that all unsatisfactory firms improve their accident performance, whether or not a return visit is made by the inspector. The initially unsatisfactory firms now have an average accident rate that is comparable with, if not better than, that of firms rated conditional and satisfactory.*

\section{Does increased enforcement bring about a general improvement?}

The ultimate measure of the effectiveness of increased enforcement would be an improvement in the average accident performance of the industry. Firms that are found to be delinquent are coerced into improving their safety practices. Other firms would observe the enhanced visibility of enforcement officers, both under the audit program and at roadsides under the MCSAP scheme, and take corrective action.

The most reliable national figures on truck accidents show a continual improvement in heavy-truck accident rates in the 1980s. Table 9 indicates that the number of fatal truck accidents has remained almost constant despite a $30 \%$ increase in the annual mileage of combination trucks. The years 1987-1989 show a $13 \%$ improvement in accident rates compared with the preceding three-year period. However, despite the remarkable improvement in safety in 1989 , the fitting of a logarithmic time trend to the data plus a dummy variable from 1987 onward does not allow us to conclude that the improvements in safety witnessed since the start of the audit program are any greater than would be expected given the trend for increased safety throughout the $1980 \mathrm{~s}$.

Table 9. Heavy truck fatal accident rates

\begin{tabular}{cccc}
\hline Year & Fatal accidents & Billion truck miles & Rate \\
\hline 1976 & 3,380 & 49.680 & 68.0 \\
1977 & 3,870 & 55.682 & 69.5 \\
1978 & 4,351 & 62.992 & 69.1 \\
1979 & 4,597 & 66.992 & 68.6 \\
1980 & 4,036 & 68.678 & 58.8 \\
1981 & 4,390 & 69.134 & 63.5 \\
1982 & 3,754 & 66.668 & 56.3 \\
1983 & 3,960 & 69.754 & 56.8 \\
1984 & 4,178 & 77.367 & 54.0 \\
1985 & 4,241 & 79.600 & 53.3 \\
1986 & 4,175 & 81.833 & 51.0 \\
1987 & 4,147 & 86.334 & 48.0 \\
1988 & 4,253 & 90.158 & 47.2 \\
1989 & 4,048 & 95,567 & 42.4 \\
\hline
\end{tabular}

Data: Fatal accidents involving trucks over $26,000 \mathrm{lbs}$ recorded in the "Fatal Accident Reporting System" from the National Highway Traffic Safety Administration. FHWA.

Miles are total miles for combination trucks reported by the

* Similar inferences were not made about firms rated conditional, because these firms have lower accident rates than satisfactory firms. 


\section{CONCLUDING REMARKS}

Our research reveals that the audits can improve the safety standard of the worst part of the industry. The difference in accident rates between the unsatisfactory firms and those rated conditional and satisfactory can be eliminated by reinspection.

However, only $5 \%$ of the industry is rated unsatisfactory. If all unsatisfactory firms improved, the overall accident rate of the industry would fall by $1.8 \%$, and the fatality and injury rate would fall by $2.1 \%$. Even these modest improvements are based on the questionable assumption that the effects of inspections are felt industry-wide. It is clear that for most firms the probability of inspection is small and the probability of reinspection and possible enforcement action is even smaller. Economic theory suggests that for a program to be successful it must have one of two characteristics. Either the probability of being caught is small but the penalties are high, or the probability of being caught is high and the penalties small (Becker 1968). It is clear the existing safety audit program satisfies neither of these conditions.

What may be viewed as even more discouraging is our conclusion that, for the most part, the particular issues probed by the inspectors have little to do with the accident performance of firms when they are out on the road. The weighting scheme applied to the various questions in order to determine a rating also appears to be deficient. While the inspection does well in targeting compliance with regulations on accident reporting and drivers' hours of service, it is misdirected in other areas. More attention should be given to whether a firm employs a safety director and whether background checks are conducted on potential new hires. The parts of the inspection dealing with financial responsibility and compliance with driving regulations and most of the questions dealing with maintenance do not appear to be related to a firms' accident risk. We recommend reform of the weighting scheme, since certain parts of the questionnaire are effective predictors of a firms' accident risk, particularly in the case of fatalities and injuries.

Given the limited resources the government has, our research leads us to the conclusion that it would be far more effective for the FHWA to target those firms that have high accident rates. Calculation of such rates would require the regular collection of mileage data from firms. Subsequent inspections of firms with poor accident records should result in the assessment of large penalties for infractions of those parts of federal regulations that are significantly related to accident performance.

Acknowledgements - The authors acknowledge the financial support of the U.S. Department of Transportation through its Centers of Excellence grant to the Great Lakes Center for Truck Transportation Research, University of Michigan, Ann Arbor. We also acknowledge the research assistance of Steven Albert, Tim Krick, Dan Pikelny, and Yajai Yod-in. We are grateful to our colleagues Bo Honoré and Robert Porter for their many helpful suggestions. We also wish to express our gratitude to the Federal Highway Administration and to Linda Giles of that Agency for some of the data employed in our research.

\section{REFERENCES}

Becker, G. S. Crime and punishment: An economic approach. Journal of Political Economy 76:168-217; 1968.

Corsi, T. M.; Fanara, P. Driver management policies and motor carrier safety. Logistics and Transportation Review 24:153-163; 1988.

Corsi, T. M.; Fanara, P. Effects of new entrants on motor carrier safety. In: Moses, L. N.; Savage, I., eds. Transportation safety in an age of deregulation. New York: Oxford University Press; 1989:241-257.

Corsi, T. M.; Fanara, P.; Roberts, M. J. Linkages between motor carrier accidents and safety regulation. Logistics and Transportation Review 20:149-164; 1984.

Moses, L. N.; Savage, I. Motor carriers of hazardous materials: Who are they? How safe are they? Proceedings of the Hazardous Materials Transport Conference. Evanston, IL: Northwestern University; 1991.

Office of Technology Assessment. Gearing up for safety: Motor carrier safety in a competitive environment. Report OTA-SET-382. Washington, DC: U.S. Government Printing Office; 1988.

Patten, M. L.; Carroll, J.L.; Thomchick, E. A. The efficacy of roadside inspections in reducing heavy truck accidents. Journal of the Transportation Research Forum 29:269-276; 1989.

Shapiro, C. Consumer information, product quality, and seller reputation. Bell Journal of Economics 13:20$35 ; 1982$.

UMTRI (University of Michigan Transportation Research Institute). Large truck survey program. Proceedings of the National Truck Safety Symposium. Washington, DC: Motor Vehicle Manufacturers Association; 1987. 
U.S. General Accounting Office. Truck safety: Improvements needed in FHWA's Motor Carrier Safety Program. Report GAO-RCED-91-30. Washington, DC: U.S. Government Printing Office; 1991.

U.S. Senate, Committee on Commerce, Science and Technology. Motor carrier safety and the Federal Highway Administration's education and enforcement efforts: Operations intended to improve an overloaded system. Washington, DC: U.S. Government Printing Office; 1989.

U.S. Senate, Appropriations Committee. Appropriations hearings on the 1990 federal budget. Washington, DC: U.S. Government Printing Office; 1989. 